\title{
Walking after incomplete spinal cord injury using an implanted FES system: A case report
}

\author{
Elizabeth Hardin, PhD; ${ }^{*}$ Rudi Kobetic, MS; Lori Murray, PT, MS; Michelle Corado-Ahmed, PT, MS; Gilles \\ Pinault, MD; Jonathan Sakai, MME; Stephanie Nogan Bailey, BSE; Chester Ho, MD; Ronald J. Triolo, PhD \\ Cleveland FES Center, Louis Stokes Cleveland Department of Veterans Affairs Medical Center, Cleveland, $\mathrm{OH}$
}

\begin{abstract}
Implanted functional electrical stimulation (FES) systems for walking are experimentally available to individuals with incomplete spinal cord injury (SCI); however, data on short-term therapeutic and functional outcomes are limited. The goal of this study was to quantify therapeutic and functional effects of an implanted FES system for walking after incomplete cervical SCI. After robotic-assisted treadmill training and overground gait training maximized his voluntary function, an individual with incomplete SCI (American Spinal Injury Association grade C, cervical level 6-7) who could stand volitionally but not step was surgically implanted with an 8-channel receiver stimulator and intramuscular electrodes. Electrodes were implanted bilaterally, recruiting iliopsoas, vastus intermedius and lateralis, tensor fasciae latae, tibialis anterior, and peroneus longus muscles. Twelve weeks of training followed limited activity post-surgery. Customized stimulation patterns addressed gait deficits via an external control unit. The system was well-tolerated and reliable. After the 12-week training, maximal walking distance increased (from $14 \mathrm{~m}$ to $309 \mathrm{~m}$ ), maximal walking speed was 10 times greater (from $0.02 \mathrm{~m} / \mathrm{s}$ to $0.20 \mathrm{~m} / \mathrm{s}$ ), and physiological cost index was 5 times less (from 44.4 beats $/ \mathrm{m}$ to 8.6 beats $/ \mathrm{m}$ ). Voluntary locomotor function was unchanged. The implanted FES system was welltolerated, reliable, and supplemented function, allowing the participant limited community ambulation. Physiological effort decreased and maximal walking distance increased dramatically over 12 weeks.
\end{abstract}

Key words: ambulation, FES, functional outcomes, locomotion, neurological gait disorders, physiological cost index, rehabilitation, spinal cord injury, stimulation, walking.

\section{INTRODUCTION}

The incidence of incomplete spinal cord injuries (SCIs) is increasing because of improved motor vehicular safety and better early care [1]. Although incomplete SCIs are usually less severe than complete injuries, they limit participation in society, restrict opportunities, and compromise health [2]. Medical advances such as antibiotic treatments for urinary tract and respiratory infections have substantially improved the health and longevity of those with incomplete SCI, but their daily lives are

\footnotetext{
Abbreviations: ASIA $=$ American Spinal Injury Association, $\mathrm{BP}=$ breakpoint, BWS-TT = body-weight-supported treadmill training, $\mathrm{CV}=$ coefficient of variation, $\mathrm{EMG}=$ electromyographic, FAC = Functional Ambulation Category, FES = functional electrical stimulation, MET = metabolic equivalent, MMT = manual muscle test, OGW = overground walking, $\mathrm{PCI}=$ physiological cost index, RF = respiration frequency, $\mathrm{SCI}=$ spinal cord injury, SCI-FAI $=$ SCI Functional Ambulation Inventory, TFL = tensor fasciae latae, $\mathrm{TV}=$ tidal volume, $\dot{\mathrm{V}}_{2}=$ oxygen consumption.

*Address all correspondence to Elizabeth Hardin, PhD; Motion Study Laboratory 151A, Cleveland FES Center, Louis Stokes Cleveland Department of Veterans Affairs Medical Center, 10701 East Boulevard, Cleveland, OH 44106; 216-791-3800, ext 4698; fax: 216-231-3433. Email: ehardin@fes.case.edu
}

DOI: 10.1682/JRRD.2006.02.0013 
mainly sedentary. As a result, these individuals have a greater risk of developing life-threatening health problems such as heart disease and type 2 diabetes than nonsedentary individuals [3-4].

Functional electrical stimulation (FES) has been used therapeutically to improve the health and independence of persons with paraplegia by activating and coordinating paralyzed lower-limb muscles, improving cardiovascular fitness [5], and decreasing the risk of diabetes [6], as well as reducing osteoporosis [7] ${ }^{*}$ without adverse effects on the insensate joints [8]. Preliminary studies suggest that FES exercise and weight bearing also reduce the risk of pressure sores by improving tissue oxygen levels, increasing muscle bulk, and altering seated pressure distribution [9].

In addition to the therapeutic uses of FES, nonambulatory individuals with partial paralysis can combine their remaining motor, sensory, and proprioceptive functions [10-11] with an FES neuroprosthesis to perform such challenging tasks as ambulation. Current neuroprosthetic technology can facilitate walking for exercise at physiological costs similar to walking in braces [12-16]. This technology offers these individuals the potential for brace- and wheelchair-independent mobility with the benefits of exercise, as well as increased independence and, in some cases, functional or community ambulation [17-20]. However, current technology using surface and percutaneous electrodes has distinct disadvantages. Systems using percutaneous electrodes are prone to infection if poorly maintained, and systems using surface electrodes make donning and doffing difficult [21-22]. Moreover, as the number of channels increases, surface electrodes become impractical and inconvenient, making them generally best suited for short-term therapeutic applications. In addition, selectively activating individual muscles deep to the skin (such as the hip flexors) with surface stimulation or obtaining repeatable stimulated responses from day to day is difficult or impossible [23-25].

Fully implanted pacemaker-like systems, on the other hand, offer numerous advantages over surface and percutaneous stimulation for long-term clinical use, including improved convenience, cosmesis, reliability,

* Betz RR, Rosenfeld E, Triolo RJ, Robinson DE, Gardner ER, Maurer A. Bone mineral content in children with spinal cord injury. Poster presented at American Spinal Injury Association Annual Meeting. San Diego, CA; 1998. and repeatability [26]. In these systems, muscle or nervebased electrodes are installed surgically and connected to an implanted stimulation device, so no material crosses the skin. Power and stimulus control information is transmitted through the skin via an inductive link, eliminating the need for problematic external switches and bodymounted sensors. Although surface and percutaneous FES technologies have been developed and used by many laboratories worldwide for decades [11,14,21$22,25]$, we present the deployment of implantable technology from our center that may surmount the challenges of ambulation after incomplete paralysis.

The purpose of this study was to quantify the therapeutic and functional effects of an implanted FES system on walking after incomplete cervical SCI. Maximal walking distance was the main outcome after baseline voluntary recovery was maximized with aggressive robotic-assisted body-weight-supported treadmill training (BWS-TT). We hypothesized that exercise and gait training with FES would improve voluntary motor control and baseline volitional walking ability and increase the strength, endurance, and repeatability of muscle contraction over maximal pre-implant levels. We then tested this hypothesis with quantitative pre- and post-implant assessments of gait function (speed, distance, symmetry, and physiological cost), as well as isokinetic muscle contractile properties (strength, endurance, and repeatability) of the knee extensors on a dynamometer. The therapeutic benefits of implanted FES on volitional muscle strength, cardiovascular health, and walking ability were established through comparison of pre- and post-implant measures. Our goal was to increase a nonambulatory individual's function to the level of independent household or limited community ambulation.

This study is innovative in that it used an implanted multichannel pulse generator and surgically implanted stimulating electrodes. It is also unique both in its focus on cervical-level incomplete SCI and its application of preparatory robotic-assisted BWS-TT to maximize voluntary function prior to application of FES.

\section{METHODS}

Deployment of the implanted neuroprosthesis encompassed (1) maximizing function via preparatory therapy; (2) identifying key muscles for stimulation to address major gait deficits; (3) inserting eight intramuscular 
electrodes to stimulate the targeted muscles of the lower limb, pelvis, and trunk; (4) synthesizing coordinated movements via patterns of intramuscular stimulation that were customized to the individual gait deficits according to established tuning algorithms [27]; and (5) adopting rehabilitation and evaluation techniques to measure the effectiveness of the system.

\section{Subject}

We report here on one participant from an ongoing study. The institutional review board of the Louis Stokes Cleveland Department of Veterans Affairs Medical Center, Cleveland, Ohio, approved this study. Criteria for inclusion in the study were (1) skeletal maturity, (2) low cervical SCI, (3) American Spinal Injury Association (ASIA) Impairment Scale grade C (motor and sensory sparing), (4) $>6$ months post-injury (neurological and emotional stability), (5) intact and electrically excitable lower motor neurons, (6) absence of psychological problems or chemical dependency, (7) range of motion within normal limits, (8) no acute orthopedic or medical complications, and (9) adequate social support and stability to comply with follow-up procedures. The minimum functional requirements for acceptance into the study were standing ability with no more than one knee braced and being either nonambulatory or physiologically ambulatory; that is, the individual could take no more than one or two voluntary steps with great difficulty. Preference was given to candidates unable to initiate a step.

The subject of this case report was 22 years old and 18 months post-injury at the time of study enrollment (body mass $=61.4 \mathrm{~kg}$, height $=1.48 \mathrm{~m}$ ). . He presented with a cervical 7 motor and cervical 6 sensory incomplete SCI and could stand but not initiate a step with either leg. The participant met our inclusion criteria for surgical FES applications, and we obtained his informed consent to participate.

\section{Participation Timeline}

The participant was evaluated on a battery of baseline biomechanical and functional measures at several time points during the study (Figure 1): (1) after the preparatory therapy and before implantation of the neuroprosthesis (pre-implant), (2) after the implant but before training ( 0 weeks), (3) after 6 weeks of training ( 6 weeks), and (4) after 12 weeks of training (12 weeks). The preimplant preparatory therapy consisted of a customized program of exercise, robotic-assisted partial BWS-TT (with the Lokomat, Hocoma AG, Volketswil, Switzerland), and overground walking (OGW) with surface stimulation. The measures collected after preparatory therapy and before implant were modified Ashworth score [28], ASIA Sensory Motor score [29], observational gait analysis, and energy cost. The following assessments were made at 0,6 , and 12 weeks post-implant to document changes due to training with the implanted neuroprosthesis: volitional contractile properties, mechanical gait analysis, 6 min walk test, maximal walking distance, and energy cost. In addition, ambulation function was assessed at baseline (pre-implant) and post-implant via two measures: (1) the Functional Ambulation Category (FAC) [30] and (2) the Spinal Cord Injury Functional Ambulation Inventory (SCI-FAI) [31].

\section{Preparatory Therapy}

To maximize voluntary function and therapeutic response to activity, the subject participated in 36 preparatory training sessions over the 8 weeks prior to implantation. As part of the preparatory therapy, the participant walked using surface stimulation and in a roboticassisted gait trainer while bearing 60 percent of his body weight. During these preparatory sessions, his cumulative walking distance ranged from $100 \mathrm{~m}$ to $1,500 \mathrm{~m}$ per session, with a heart rate between $90 \mathrm{bpm}$ and $165 \mathrm{bpm}$. Gains in muscle girth were indicated by our need to increase the lower-leg cuff size in the Lokomat by $4 \mathrm{~cm}$ from the initial to final training sessions. The participant exhibited decreased number and severity of spasms over the course of preparatory training and also self-reported reduced spasms at home. No improvement in OGW was noted; he remained nonambulatory.

\section{Baseline Assessments}

After preparatory therapy and before implantation, the participant's spasticity and muscle tone were formally evaluated with the modified Ashworth scale [28] and his spasticity, sensation, and volitional strength were assessed with the ASIA Sensory Motor Evaluation [29] (Figure 1). Walking ability was assessed with the FAC [30], and the SCI-FAI [31] was applied to further classify walking ability through assessment of several ambulation categories: gait parameters, assistive devices, and walking mobility. A higher score indicated a higher quality gait that was less dependent on assistive devices and more functional and thus more likely to influence activities of 
daily living, community ambulation, and walking for exercise.

An observational gait analysis was performed during the baseline evaluation to subjectively identify ambulatory deficits and target muscles for implantation. The participant walked with bilateral surface stimulation. Different combinations of up to eight channels of stimulation of the trunk extensors, hip and knee flexors and extensors, and ankle plantar- and dorsiflexors were evaluated to identify muscles for implantation. Standard tuning rules developed in our laboratory were applied to optimize stimulation patterns for walking [27]. Temporal patterns of stimulation were constructed to augment residual voluntary motion, activate completely paralyzed muscles, and reduce extensor tone for improved ambulation. The patterns were based on the unique stimulated responses of the participant's muscles to generate the strongest muscle contraction without overflow to other muscle groups and within sensory tolerance, as in our previous work [27]. Bilateral stimulation of the quadriceps, tibialis anterior, hamstrings, and erector spinae allowed the participant to walk an average of $11 \mathrm{~min}$ at
$0.02 \mathrm{~m} / \mathrm{s}$. The observational gait analysis from surfacestimulation walking and the participant's feedback identified key muscular deficits that impaired walking; these deficits were targeted for the implanted FES system.

\section{Implanted System Implementation}

During baseline evaluation and preparatory training with surface stimulation, key muscles were identified to address the following major gait deficits: lack of terminal swing-phase extension, absent hip flexion, and ankle dorsiflexion. Based on this determination, intramuscular electrodes [32] were surgically implanted bilaterally in the following muscles: (1) iliopsoas for hip flexion, (2) tensor fasciae latae (TFL) for hip flexion and abduction, (3) vastus intermedius and lateralis for knee extension, and (4) tibialis anterior and peroneous longus for ankle dorsiflexion. The intramuscular electrode leads were tunneled subcutaneously and connected to an 8-channel receiverstimulator (IRS-8, not commercially available) [33] implanted in the subcutaneous fat of the lower-left quadrant of the abdomen (Figure 2). The electrode leads were connected to the IRS-8 with in-line connectors [34]. The

\begin{tabular}{|c|c|c|}
\hline Implantation & $\mathrm{Ga}$ & $\begin{array}{l}\text { Post-implant } \\
\text { Evaluation }\end{array}$ \\
\hline $\begin{array}{c}\text { Entry } \\
\begin{array}{c}\text { Preparation } \\
8 \text { weeks }\end{array}\end{array}$ & $\begin{array}{l}\text { Rest } \\
6 \text { weeks } \\
\text { (2 weeks off) } \\
\text { (4 weeks exercise) }\end{array}$ & $\begin{array}{l}\text { Post-implant } \\
\text { Training } \\
12 \text { weeks }\end{array}$ \\
\hline $\begin{array}{l}\text { Pre-implant measures-collected } \\
\text { after preparatory therapy using } \\
\text { surface FES where necessary: }\end{array}$ & & $\begin{array}{l}\text { Post-implant measures-collected before } \\
\text { training with implant ( } 0 \text { weeks), mid-training } \\
\text { (6 weeks) and after training (12 weeks): }\end{array}$ \\
\hline $\begin{array}{l}\text { Subject classification: } \\
\text { - Modified Ashworth score } \\
\text { - ASIA Sensory Motor score } \\
\text { Walking function for ADL: } \\
\text { - FAC } \\
\text { - SCI-FAI } \\
\text { - Observational gait analysis } \\
\text { Physiological status: } \\
\text { - Energy cost }\end{array}$ & & $\begin{array}{l}\text { Muscle strength: } \\
\text { - Volitional contractile properties } \\
\text { System performance: } \\
\text { - Mechanical gait analysis* } \\
\text { Walking function for ADL: } \\
\text { - FAC } \\
\text { - SCI-FAI } \\
\text { - 6-minute walk test } \\
\text { - Maximal walking distance } \\
\text { Physiological status: } \\
\text { - Energy cost }\end{array}$ \\
\hline
\end{tabular}

Figure 1.

Participation timeline for case study that consisted of pre-implant baseline and preparatory component, functional electrical stimulation (FES) system implantation, post-implant gait training, and post-implant evaluation. *Evaluated mid- and post-training (6 and 12 weeks). ${ }^{\dagger}$ Evaluated pre-implant and post-training. $\mathrm{ADL}=$ activities of daily living, ASIA $=$ American Spinal Injury Association, FAC $=$ Functional Ambulatory Category, SCI-FAI $=$ Spinal Cord Injury Functional Ambulation Inventory. 

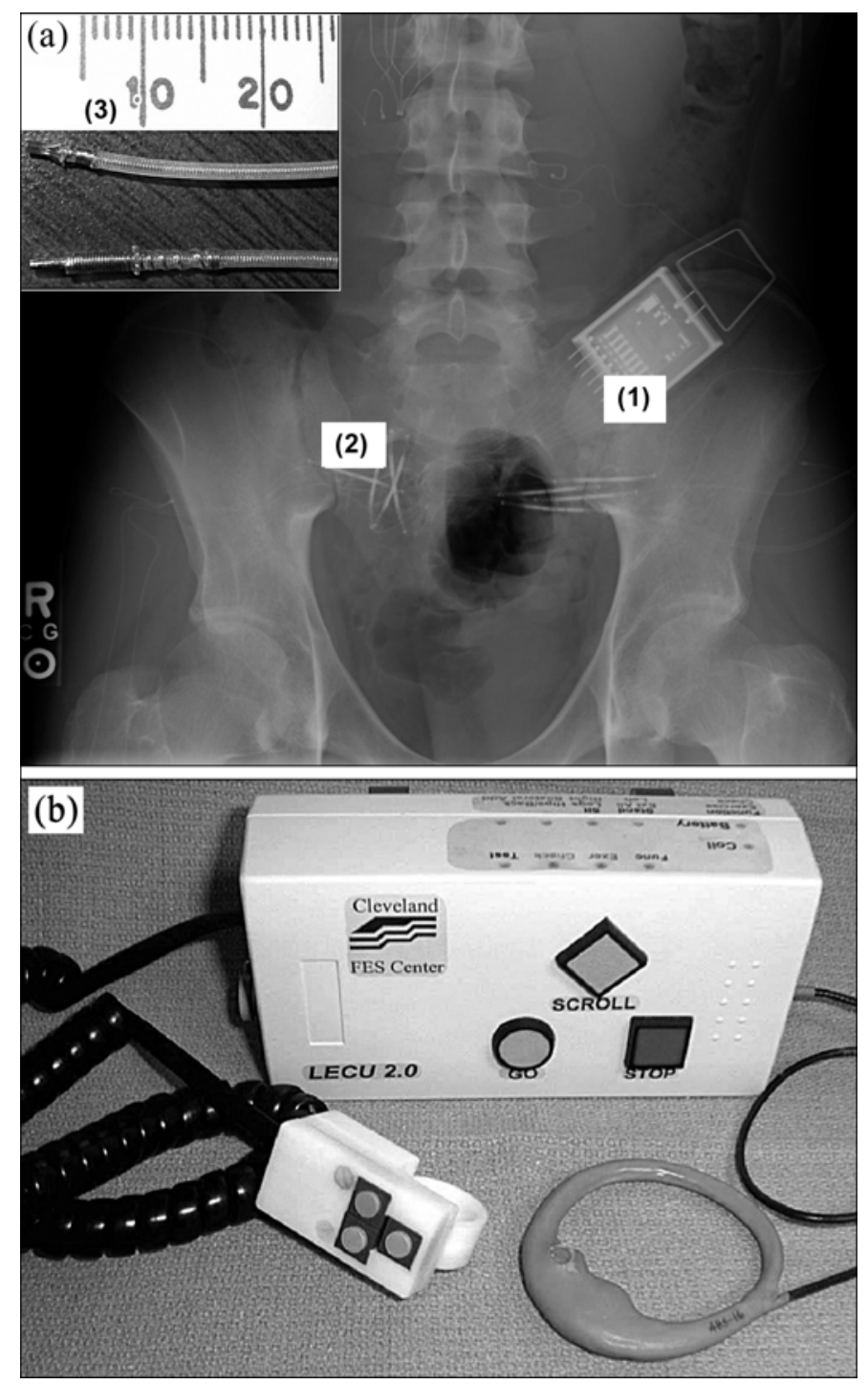

Figure 2.

Components of implanted walking neuroprostheses. (a) Implanted components: (1) IRS-8 receiver stimulator, (2) in-line connectors, and (3) intramuscular electrodes (inset, not to scale with X-ray). Inset scale is accurate for electrode; both connector and stimulating ends are shown. (b) External components: control unit, coupling coil, and finger switch that were modified for mounting on participant's walker and for hand activation.

implanted components were identical to those of the Freehand $^{\mathrm{TM}}$ system, the first motor-system neuroprosthesis to receive marketing approval. These Food and Drug Administration-approved devices have been safely and effectively installed worldwide in the upper limbs of more than 200 people with cervical SCI to provide active handgrasp or standing after paralysis without major com- plication and with documented user satisfaction [35-36]. External system components included a custom rechargeable wearable external control unit, command hand switch, transmitting coil, charger, and clinical programming station [37].

Electrodes were profiled 1 week after implantation and monthly thereafter to establish stimulus thresholds and maximal values of pulse duration. We determined thresholds by slowly increasing pulse duration of a $20 \mathrm{~mA}$ biphasic, charge-balanced stimulus at $20 \mathrm{~Hz}$ until twitches were generated. We obtained maximal pulse durations by increasing the stimulation until (1) no additional force was generated by the muscle, (2) stimulation recruited unwanted muscles, or (3) reflex activity or adverse sensation was observed. At the maximal pulse duration, stimulated strength was graded on a modified version of the manual muscle test (MMT) [38].

To facilitate healing, the participant was prescribed 6 weeks of limited transfers after the implantation surgery. At 2 weeks post-implant, the participant began a 4-week progressive exercise period to rebuild strength and tolerance to stimulation. Following this period, the participant initiated 12 weeks of gait training and exercise during which he participated in 36 sessions using a walker for support. Temporal patterns of stimulation for exercise and walking were defined by stimulation threshold, maximal pulse duration, and MMT. Contraction strength was adjusted first by modulation of stimulus pulse width and second by modulation of stimulus frequency to minimize fatigue. We coordinated movements of the participant's limbs by adjusting the timing of the stimulation pattern, advancing or delaying the relative phasing of various muscle activations based on the tuning process described previously for surface stimulation and on observation of the resulting motion in real time slow motion videotape analysis and feedback from the participant that continued until the most symmetrical, fast, and comfortable gait was achieved.

\section{Stimulation Pattern}

The walking provided by the implanted neuroprosthesis is illustrated in Figure 3, along with the temporal pattern of stimulation customized for the specific needs of the participant. The stimulation pattern was divided into segments separated by breakpoints (BPs) at which various command inputs and control actions could occur. Progression through the pattern could be delayed at a specified BP to wait for trigger input signals from a finger 
switch or other sensor. The participant was given a hand switch to manually trigger each step and was trained to use it proficiently. In the stimulation pattern constructed specifically for this implant recipient (Figure 3(c)), a step with the left leg was triggered by depression of the finger switch at BP1, which activated the left hip flexors and ankle dorsiflexors (iliopsoas, TFL, and tibialis anterior) and initiated swing. The left vasti (quadriceps) were activated for terminal extension and weight acceptance at BP3 to complete the left step. The pattern dwelled in double support with the participant standing under his own volition at BP5 until the manual trigger was depressed again to activate the right hip flexors and dorsiflexors (iliopsoas, TFL, and tibialis anterior) and thereby initiate right leg swing. The right vasti (quadriceps) were activated at BP4 to complete the right step at BP9, at which time the pattern looped back to the beginning to await another switch depression to repeat the cycle. Because no stimulation was delivered while the participant awaited the switch triggers (just before BP1 and at BP5), he could continue to step in this manner until he chose to sit down under his own volition. In addition to manually triggering each step with successive switch depressions, the subject could also automatically cycle through the pattern, continuously repeating the gait cycle until he chose to cease stepping by pressing the finger switch. Stimulus timing information and power to the implant were provided by a programmed external control unit via radio frequency coupling [37].

\section{Gait Training with Implanted Neuroprosthesis}

The customized 12-week exercise and gait training program consisted of daily exercise at home and two to three supervised gait training sessions a week in the laboratory. The daily exercise routine involved patterns of stimulation designed to strengthen muscle (few repetitions at maximal loads) and exercises to build endurance (many repetitions at minimal loads). Laboratory sessions initially consisted of both BWS-TT and OGW with patterns of stimulation individualized to the participant's abilities. Body-weight support was determined by the minimal amount of support required for the participant to achieve the highest gait quality, with a target of $<30$ percent body-weight support [39]. The participant was instructed to ambulate at his fastest comfortable walking speed while maintaining optimal gait quality during OGW; distance and time were recorded during each session to gauge progress. Sessions lasted 1.5 hours, with the participant determining training and resting periods. The participant continued with solely OGW once he completed two sessions of combined training (OGW and BWS-TT) and showed consistency of gait with and without body-weight support. Heart rate, blood pressure, and rate of perceived exertion were monitored throughout the gait training sessions.

\section{Outcome Measures}

Quadriceps muscle contractile properties were measured pre- and post-implant. Data were collected over 3 separate days with an isokinetic dynamometer (Biodex Pro System 3, Shirley, New York) at 30 percent during the following conditions: volitional effort, FES alone, and FES combined with volitional effort. Ten repetitions were performed for each condition, with maximal contractions separated by $30 \mathrm{~s}$ rest periods.

Mechanical gait analysis was performed mid- and post-training (6 and 12 weeks) with a seven-camera Vicon motion capture system (Vicon, Oxford, United Kingdom) for six walking trials. Post-preparatory therapy (pre-implant) mechanical gait analysis with surface stimulation was not collected because the participant required a supportive platform walker that interfered with the collection of passive marker trajectories. Temporal and spatial gait data were collected at $60 \mathrm{~Hz}$ with the modified Helen Hayes Marker set [40-41] used to derive gait parameters. Parameters of interest were calculated with the Vicon Polygon software and included step length and walking speed for six right and six left steps. Repeatability was determined with the coefficient of variation (CV) expressed as a percentage.

Cardiovascular and physiological performance measures were collected during resting and walking, preimplant and post-training. The pre-implant metabolic data were collected with eight channels of surface stimulation to achieve stepping after preparatory therapy. We administered the 6 min walk test before and after exercise and gait training using a continuous walking route in the hospital hallways outside the laboratory [42]. Sitting heart rate and oxygen consumption ( $\dot{\mathrm{V}}_{2}$ ) data were measured before walking while the participant sat in a chair for $5 \mathrm{~min}$. A wearable metabolic analyzer was used to record breath-by-breath gas exchange, ambulatory energy consumption, and cardiopulmonary function, including metabolic equivalents (METs) (Cosmed K4 b2, Cosmed, Rome, Italy); heart rate was measured with a wearable monitor (Polar Vantage XL, Polar Electro Inc, Lake Success, New York). An MET expresses energy expenditure rate relative 


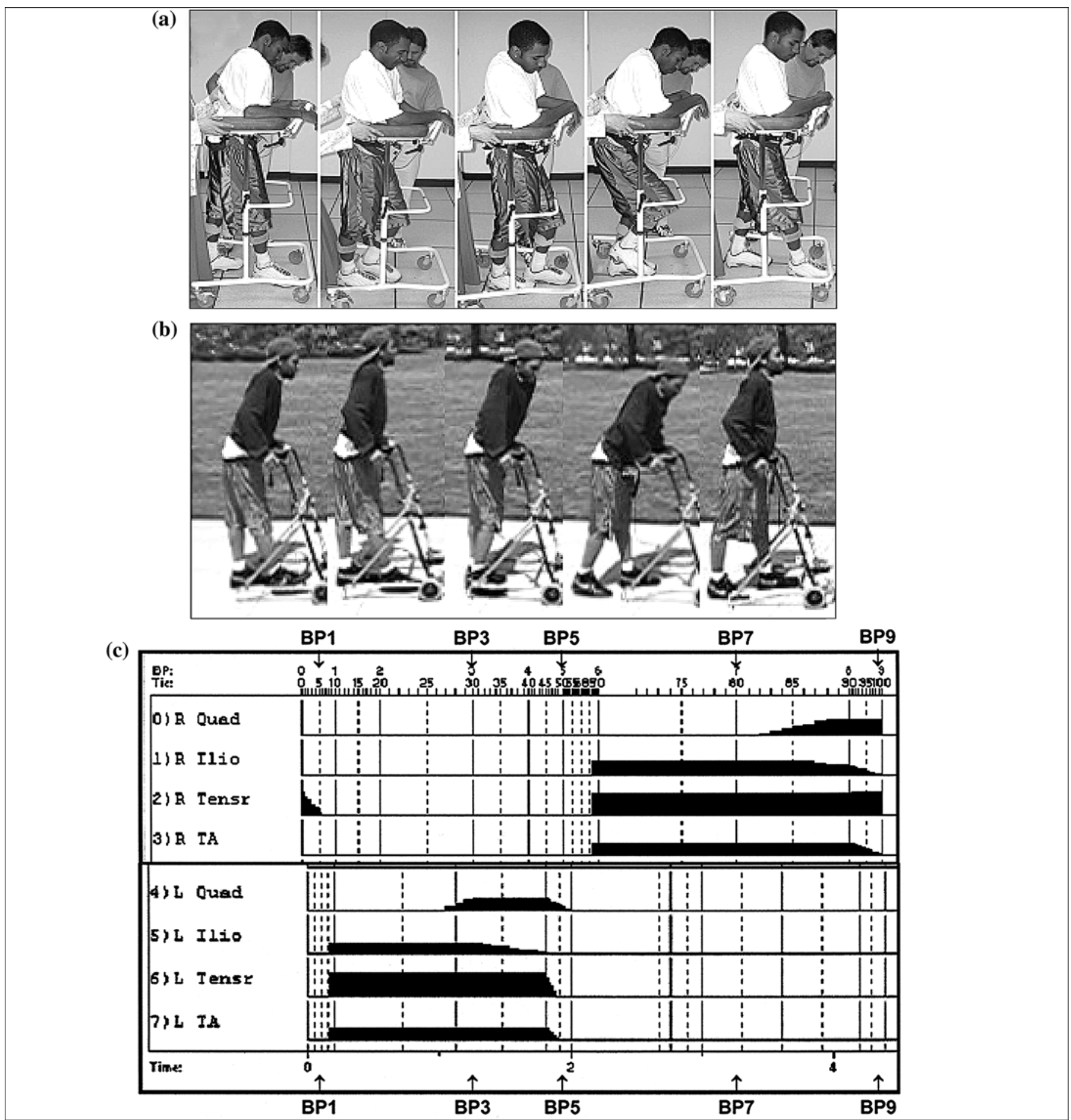

Figure 3.

Participant's walking ability differed greatly between pre- and post-implant periods. (a) During baseline (pre-implant) evaluation, participant walked with 8 channels of surface stimulation and required considerable balance aid. (b) During post-implant training, participant walked with 8 channels of stimulation via implanted neuroprostheses and required less balance aid. (c) Temporal patterns of stimulation (pulse duration) for walking were programmed into memory of control unit. Stimulation was delivered to vastus intermedius/lateralis (Quad), iliopsoas (Ilio), tensor fasciae lata (Tensr), and tibialis anterior (TA) muscles on right (R) (muscles 0-3) and left (L) sides (muscles 4-7). BP = breakpoint. 
to the resting state; $1 \mathrm{MET}$ is the oxygen cost of being at rest and equals $3.5 \mathrm{~mL} / \mathrm{kg} / \mathrm{min}$ of oxygen used per body weight per minute of activity. After the sitting data were collected, the participant then walked as fast and as far as possible in a 6 min period. Walking distance and elapsed time were collected and used with heart rate data to calculate physiological cost index (PCI), the ratio of change in heart rate to walking velocity, which is highly correlated with metabolic energy cost [43]. Maximal walking distance was measured on a continuous walking route through the hospital hallways, with the endpoint decided by the participant. FAC and SCI-FAI were assessed preand post-implant during these walking sessions.

Intermediate data were collected for some assessments at 6 weeks to assess progress and at pre- and posttraining intervals to determine the training effect of the system (Figure 1). Repeated measures analysis of variance was used to analyze the results for changes in contractile properties and gait mechanics due to training with the neuroprosthesis. Clinical significance was set at a 20 percent difference in parameters [44], a $0.2 \mathrm{~m} / \mathrm{s}$ increase in walking speed, and a move from classification as a nonambulator to a household or community ambulator. The increase in walking speed was chosen because it has been related to individuals who can independently perform at least one activity of daily living [45].

\section{RESULTS}

At baseline, the participant exhibited a marked hip extensor tone during hip flexion movement. Pre-implant MMT showed no active movement against gravity in all muscles below the level of injury. After the aggressive pre-implant preparatory therapy, volitional MMT showed only very slight muscle strength improvements from preto post-implant, the largest of which were in the distal lower limb muscles, the long toe extensors, and ankle plantarflexors. Additionally, there were small improvements in the hip flexors and abductors and left knee flexors (Table 1); however, more importantly, the participant was still classified via FAC as a nonfunctional ambulator [46] and had an SCI-FAI score of zero in each category.

After the neuroprosthesis was implanted and the participant had 12 weeks of training with it, his post-training maximal walking distance increased by 20 times, from an initial distance of $14 \mathrm{~m}$ in $11 \mathrm{~min}$ to a post-training distance of $309 \mathrm{~m}$ in $30 \mathrm{~min}$. His maximal post-training walking speed increased by 10 times from $0.02 \mathrm{~m} / \mathrm{s}$ to
$0.20 \mathrm{~m} / \mathrm{s}$ (Table 2), and this moved him from a nonambulator to a limited independent community ambulator (Figure 4).

Voluntary knee extension moments did not change pre- to post-implant, and knee extension moment either with or without FES did not significantly increase (Table 3). FES reduced variability as determined by the $\mathrm{CV}$ of knee extension moment between efforts compared with volitional effort alone. FES also produced a more sustained knee moment over the range of knee angles.

Pre- to post-implant sitting metabolic data indicated increased general cardiopulmonary health. In addition, the physiological cost of walking dramatically decreased with use of the implanted FES system. Pre-implant walking metabolic data were collected with eight channels of surface stimulation, which allowed a maximal speed of $0.02 \mathrm{~m} / \mathrm{s}$. Post-implant walking data were collected at

Table 1.

Participant's pre- and post-implant muscle strength from manual muscle testing. Pre-implant measures were collected prior to pre-implant training, and post-implant measures were collected to demonstrate strength changes due to preparatory training (before training with implant).

\begin{tabular}{lcccccc}
\hline \multirow{2}{*}{ Muscle } & \multicolumn{2}{c}{ Right Side } & & \multicolumn{2}{c}{ Left Side } \\
\cline { 2 - 3 } \cline { 5 - 6 } & Pre & Post & & Pre & Post \\
\hline Hip Flexors & 2 & $3-$ & & $3-$ & 3 \\
Hip Extensors & $2+$ & 1 & & $2+$ & 2 \\
Hip Abductors & 1 & $2-$ & & 2 & $2+$ \\
Hip Adductors & $2+$ & $2+$ & & $2+$ & $2+$ \\
Knee Extensors & $3-$ & $3-$ & & $3-$ & $3-$ \\
Knee Flexors & 1 & 1 & & 1 & $2-$ \\
Ankle Dorsiflexors & 1 & 1 & & 2 & $2+$ \\
Ankle Plantarflexors & 1 & $2-$ & & $2-$ & $2+$ \\
Long Toe Extensors & 0 & 2 & & 0 & 1 \\
\hline \hline
\end{tabular}

Table 2.

Participant's gait parameters and Spinal Cord Injury Functional Ambulation Inventory (SCI-FAI) scores significantly improved during 12-week training with the implanted functional electrical stimulation system.

\begin{tabular}{lccc}
\hline \multicolumn{1}{c}{ Measure } & 0 Wk & $\mathbf{6 ~ W k}$ & 12 Wk \\
\hline Maximum Distance (m) & 14 & 200 & 309 \\
Maximum Time (min) & 11 & 20 & 30 \\
Maximum Speed (m/s) & 0.02 & 0.17 & 0.20 \\
SCI-FAI & & & \\
$\quad$ Gait Parameters & $0^{*}$ & - & $18 / 20$ \\
Assistive Devices & $0^{*}$ & - & $8 / 14$ \\
Walking Mobility & $0^{*}$ & - & $3 / 5+5.7 \mathrm{~m} / \mathrm{min}$ \\
\hline Pre-implant. & & & \\
\hline \hline
\end{tabular}




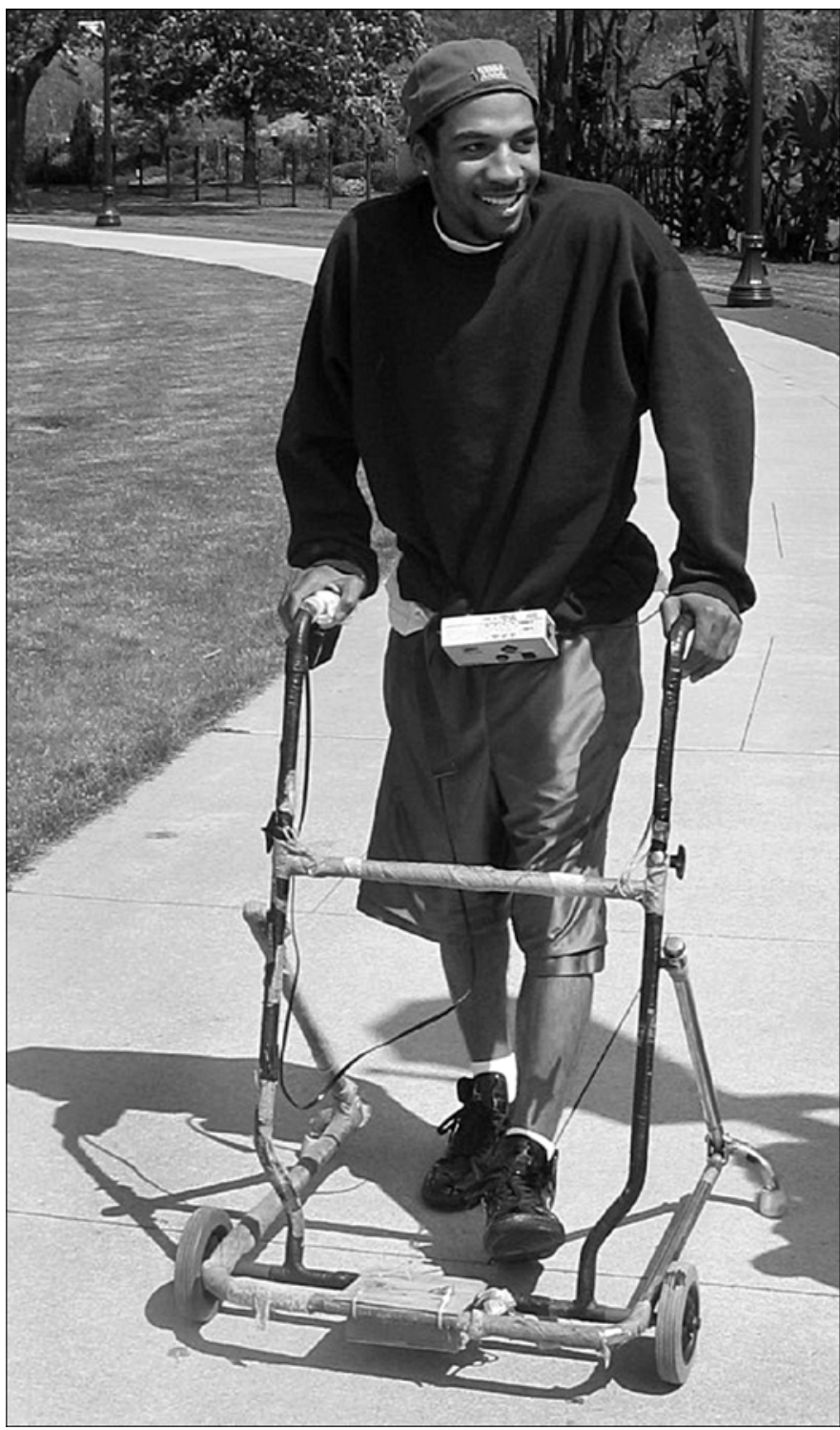

Figure 4.

After 12 weeks of training with implanted neuroprothesis, participant's Functional Ambulation Category improved from nonfunctional (0, no walking ability) to independent (4). Participant could walk independently in community.

$0.17 \mathrm{~m} / \mathrm{s}$ after 12 weeks of training with the implanted FES system. Tidal volume (TV) did not change pre- to post-implant during sitting or walking (Table 4). However, sitting ventilation decreased, a function of decreased respiration frequency (RF), while walking ventilation increased because of small increases in both RF and TV of approximately 20 percent. Mean \pm standard deviation values are displayed. Walking $\dot{\mathrm{V}}_{2}$ increased slightly. Sitting METs, however, were less after training with the implant, signifying that resting energy expenditure had decreased. METs were greater during post-implant walking at increased speed. PCI decreased dramatically, from 44.4 beats $/ \mathrm{m}$ to 8.6 beats $/ \mathrm{m}$, because of increased speed.

Temporal and spatial gait parameters were collected with the neuroprosthesis at midway through training with the implant and at post-training. Walking speed increased significantly and repeatability improved with training for all parameters. Repeatability increased for every gait parameter calculated from the temporal and spatial data (Table 5). Several measures changed significantly by $>20$ percent from mid-training to post-training. Significant increases were observed in walking speed, right side stride length, and right side step length. Significant decreases were observed in time spent in left single support.

When using the neuroprosthesis, the participant's FAC improved from nonfunctional (0, no walking ability) to independent (4). The participant could walk independently on level ground with the implanted FES system but required standby assistance on uneven surfaces. His pre-implant SCI-FAI scores improved from 0 in all categories to 18/20 in Gait Parameters, 8/14 in Assistive Devices and 3/5+ $5.7 \mathrm{~m} / \mathrm{min}$ in Walking Mobility postimplant and post-training (Table 2). Moreover, postimplant walking required less physical assistance and a less cumbersome balance aid than walking with surface stimulation during baseline evaluation (Figure 3), the participant's posture was more erect, and reliance on the withdrawal reflex, which tends to habituate over time and vary from step to step, was not necessary. These improvements signify the greater reliability of stimulation delivery and the opportunity for increased independence. More importantly, the participant has not experienced infections or other adverse reactions to the implanted components or device failures, such as wire breakage or electronic malfunction.

\section{DISCUSSION}

This case study presents the evaluation of an FES intervention and the therapeutic and functional effects of 12 weeks of gait training with an implanted FES system, as well as the neuroprosthetic effects. The implanted components were used in a novel way and were welltolerated by the participant. Stimulated responses were stable and consistent, and strong, repeatable contractions were elicited well below the tolerable limits of sensation. 
JRRD, Volume 44, Number 3, 2007

Table 3.

Pre- and post-implant isokinetic knee extension moment data were collected under volitional, functional electrical stimulation (FES), and FES + volitional conditions.

\begin{tabular}{|c|c|c|c|c|}
\hline \multirow{3}{*}{ Condition } & \multicolumn{4}{|c|}{ Knee Extension Moment (N•m) } \\
\hline & \multicolumn{2}{|c|}{ Pre-Implant } & \multicolumn{2}{|c|}{ Post-Implant } \\
\hline & Mean \pm SD & CV (\%) & Mean \pm SD & CV (\%) \\
\hline \multicolumn{5}{|l|}{ Left Knee } \\
\hline Volitional & $17.8 \pm 6.0$ & $34^{*}$ & $12.1 \pm 5.6$ & $46^{*}$ \\
\hline FES & $41.2 \pm 1.4$ & 3 & $42.6 \pm 1.9$ & 5 \\
\hline FES + Volitional & $43.9 \pm 3.9$ & $9^{*}$ & $46.8 \pm 5.4$ & $12^{*}$ \\
\hline \multicolumn{5}{|l|}{ Right Knee } \\
\hline Volitional & $24.4 \pm 8.5$ & $35^{*}$ & $29.4 \pm 7.0$ & $44^{*}$ \\
\hline FES & $27.8 \pm 2.2$ & 8 & $23.7^{\dagger} \pm 1.7$ & 7 \\
\hline FES + Volitional & $27.0 \pm 2.9$ & $11^{*}$ & $28.4^{\dagger} \pm 4.4$ & $15^{*}$ \\
\hline
\end{tabular}

${ }^{*}$ Repeatability of FES + Volitional was better than Volitional alone $(p<0.05)$ for all conditions, as signified by decreased CV.

$\dagger$ †ost-implant right knee movement with FES was less than post-implant with FES + Volitional $(p<0.05)$.

$\mathrm{CV}=$ coefficient of variation, expressed as percentage (used to determine repeatability); $\mathrm{SD}=$ standard deviation.

Table 4.

Metabolic data were collected pre- and post-implant while participant sat and walked. Pre-implant data collected at $0.02 \mathrm{~m} / \mathrm{s}$ walking speed and post-implant data collected at $0.17 \mathrm{~m} / \mathrm{s}$ walking speed. Data presented as mean \pm standard deviation.

\begin{tabular}{|c|c|c|c|c|}
\hline \multirow{2}{*}{ Metabolic } & \multicolumn{2}{|c|}{ Sitting } & \multicolumn{2}{|c|}{ Walking } \\
\hline & $\begin{array}{l}\text { Pre-Implant } \\
\end{array}$ & Post-Implant & Pre-Implant & Post-Implant \\
\hline Respiration Frequency* (breaths/min) & $21 \pm 8$ & $15.6 \pm 2.5$ & $32.7 \pm 10.5$ & $36.7 \pm 9.7$ \\
\hline Tidal Volume (L) & $0.46 \pm 0.19$ & $0.43 \pm 0.09$ & $0.65 \pm 0.24$ & $0.73 \pm 0.23$ \\
\hline Ventilation $^{*}$ (L/min) & $9.5 \pm 5.8$ & $6.8 \pm 2.2$ & $20.6 \pm 9.6$ & $25.8 \pm 7.6$ \\
\hline $\mathrm{V}{ }^{*}(\mathrm{~mL} \mathrm{O} / \mathrm{min} / \mathrm{kg})$ & $4.2 \pm 4.2$ & $2.9 \pm 1.5$ & $11.2 \pm 6.4$ & $14.3 \pm 5.5$ \\
\hline $\mathrm{HR}^{*}$ (sitting only) (bpm) & $82 \pm 3$ & $63 \pm 3$ & $166 \pm 13$ & $151 \pm 19$ \\
\hline MET $^{*}$ & $1.2 \pm 1.0$ & $0.8 \pm 0.4$ & $3.1 \pm 1.7$ & $4.1 \pm 1.6$ \\
\hline $\mathrm{PCI}^{*}$ (beats/m) & - & - & 44.4 & 8.6 \\
\hline
\end{tabular}

Note: 1 metabolic equivalent $(\mathrm{MET})=3.5 \mathrm{~mL} \mathrm{O} / \mathrm{min} / \mathrm{kg}$; indicates physical workload relative to rest.

${ }^{*}$ Significantly different change of $\geq 20 \%$ ( $p<0.05$ ) from pre- to post-training; considered clinically significant except for respiration frequency, which was significantly different for sitting only.

$\mathrm{HR}=$ heart rate, $\mathrm{PCI}=$ physiological cost index, $\mathrm{V}_{2}=$ oxygen consumption.

Exercise and gait training with a customized implanted multichannel neuroprosthesis did not improve voluntary motor control or baseline volitional walking ability, as was proposed in one of our original hypotheses. However, the implanted FES system made walking feasible that was not volitionally possible even after aggressive preparatory therapy with robotic-assisted BWS-TT and surface stimulation. The therapeutic effect of this preparatory training was thus limited and did not translate into increased function, although it ensured the highest baseline function before application of the implanted neuroprosthesis. When using the neuroprosthesis, our participant's FAC improved from nonfunctional (0, no walking ability) to independent (4). That is, he could walk independently with a rolling walker on level ground. These results sig- nify that this system is practical for household or limited community ambulation.

The MMT of the participant's strength determined at study enrollment was not indicative of his standing ability (Table 1). Voluntary muscle strength was assessed with the participant in a supine/prone position and during open-chain tasks. MMT results did not transfer to his ability to stand against gravity, a closed-chain task. This may indicate that additional metrics such as an increased extensor tone when standing and the total extension moment may be necessary to predict standing ability after incomplete SCI [47].

Subtle changes in baseline muscle strength and muscle contractile properties were also not indicative of the participant's dramatic decrease in PCI during walking. We therefore expect that these improvements were due to 
enhanced muscle endurance instead of strength, as well as to greater ventilation and $\dot{\mathrm{VO}}_{2}$ during walking pre- to post-implant.

Gains in cardiovascular function were indicated by decreased resting and working heart rate, signifying that walking in particular had become more energy efficient. The increased post-implant $\dot{\mathrm{V}}_{2}$ during walking was expected because of increased walking speed after 12 weeks of training, but this increase was meager compared with the walking speed increase. In addition, METs were increased at 12 weeks, signifying a greater degree of aerobic fitness.

Excessive hip extension tone is not uncommon among individuals with incomplete SCI, but for our participant, this tone depended on position as well as stimulation. A large amount of hip co-contraction was observed while he was standing but not when he was supine. This finding was confirmed with subsequent surface electromyographic (EMG) analysis. With electrical stimulation of the hip flexors (iliopsoas) during standing, muscle activity in the hip extensors (biceps femoris) decreased dramatically, which facilitated hip flexion for stepping. Stimulation was the means to reducing extensor tone during standing to allow stepping.
We found that the participant's walking velocity with the implanted neuroprosthesis increased with gait training (from 6 to 12 weeks) primarily by an increased stride length. The decreased time that he spent in stepping with the right foot after gait training improved his right-to-left step length symmetry, signifying an improved ability to weight-shift during walking. In addition, variability in temporal and spatial gait measures between the right and left sides decreased. These changes could indicate taskspecific strength gains on the right side or improved left to right side coordination. This increase in mechanical reliability would lessen the chance of tripping, increase mechanical efficiency, and improve walking appearance.

Although walking speed and stride length increased, walking cadence remained the same from 6 to 12 weeks of gait training. This limitation was expected because control of cadence is accomplished by pre-programmed stimulation patterns and is also limited by muscle response. In addition, the limitations in walking speed and cadence were a function of the muscle set being assisted by the implanted system. Increased walking speed is generally accomplished through increased activation of the gastrocnemius, which adds greater propulsion power to the gait cycle and increases cadence. This muscle was not

Table 5.

Post-implant gait parameters were collected midway through training with implant and at post-training. Six steps were averaged for each side. Stride parameters are given but could be derived from step parameters.

\begin{tabular}{|c|c|c|c|c|}
\hline \multirow{2}{*}{ Post-Implant Gait Parameter } & \multicolumn{2}{|c|}{ Mid-Training } & \multicolumn{2}{|c|}{ Post-Training } \\
\hline & Mean \pm SD & CV (\%) & Mean \pm SD & CV (\%) \\
\hline Cadence (steps/min) & $25.5 \pm 2.60$ & 11 & $27.5 \pm 0.66$ & 2 \\
\hline Left Step Time (s) & $1.9 \pm 0.16$ & 8 & $1.8 \pm 0.09$ & 5 \\
\hline Left Foot Off (\% cycle) & $80.8 \pm 5.37$ & 7 & $86.9 \pm 2.16$ & 2 \\
\hline Left Single Support Time (s) & $0.75 \pm 0.18$ & 25 & $0.53 \pm 0.08$ & 15 \\
\hline Left Step Length (m) & $0.27 \pm 0.13$ & 47 & $0.29 \pm 0.13$ & 44 \\
\hline Right Step Time (s) ${ }^{*}$ & $3.1 \pm 1.36$ & 43 & $2.6 \pm 0.07$ & 3 \\
\hline Right Foot Off (\% cycle) & $84.6 \pm 3.99$ & 5 & $87.8 \pm 1.91$ & 2 \\
\hline Right Single Support Time (s) & $0.84 \pm 0.19$ & 22 & $0.67 \pm 0.08$ & 12 \\
\hline Right Double Support Time (s) & $3.5 \pm 1.26$ & 37 & $3.2 \pm 0.17$ & 5 \\
\hline Right Stride Time (s) & $5.0 \pm 1.35$ & 27 & $4.4 \pm 0.09$ & 2 \\
\hline Right Stride Length (m) ${ }^{*}$ & $0.56 \pm 0.13$ & 23 & $0.68 \pm 0.10$ & 14 \\
\hline
\end{tabular}


implanted because of the channel limitation inherent in the system. Instead, the available eight channels of stimulation were prioritized according to the primary deficits that were preventing walking. The implant recipient thus relied on voluntary plantarflexion strength during walking with the neuroprosthesis and this strength was lacking (Table 1). For greater redundancy in assistance of weaker movements during walking and improvement of hip extension, a new generation of 12- and 16-channel implanted stimulators are being implemented at our center in lower limb applications and include ankle plantarflexion.

Other research centers have shown that lower limb neuroprostheses can improve the short-term therapeutic and functional outcomes of persons with incomplete SCI by demonstrating participants' improvements in step length and maximal walking velocity [17-20]. This study supplements these data by documenting additional therapeutic and functional gains, such as a greatly improved maximal walking distance, reduced physiological cost, and decreased variability of temporal and spatial gait parameters. The gains afforded by the neuroprosthesis provide insight into new opportunities for system use in activities of daily living, community ambulation, and ambulation for the systemwide benefits of load-bearing exercise. Furthermore, these results signify that this neuroprosthesis would be a feasible and safe alternative for other individuals in the future.

The implanted neuroprosthesis used in this case study is limited for use in individuals with incomplete SCI who have basic hand and arm function to assist in upper body support. Our participant used a normal walker for support after the implant, an improvement over the platform walker that he required during baseline walking evaluation with surface stimulation. Although this case report was complicated by the upper limb manual deficits inherent in our participant with cervical level injury, most previously published work concentrated on individuals with thoracic level injuries.

After post-implant evaluation, the participant was encouraged to use the neuroprosthesis for home and limited community ambulation, although at his speed, community ambulation may actually be very limited. His successful fitting with the implanted neuroprosthesis was accomplished by individualized preparation, implantation, and training/rehabilitation techniques, resulting in an effective system that provided previously nonexistent walking. This new walking ability should afford him gains in health and opportunities. Ultimately, our longterm goal is to use this system in clinical trials to restore walking to nonambulatory individuals with incomplete SCI and to improve gait in individuals who have walking difficulties.

\section{CONCLUSIONS}

Although exercise and gait training with a customized implanted multichannel neuroprosthesis did not improve voluntary motor control or baseline volitional walking ability, they successfully augmented volitional function and allowed our participant with incomplete SCI to move from nonambulation to very limited community ambulation. Practice with the system over 12 weeks decreased his physiological effort and showed the potential for continued improvements in maximal walking distance. Walking was thus a direct result of a neuroprosthetic response, whereas evidence of a neurotherapeutic effect was limited as demonstrated by the participant's lack of change in voluntary independent walking ability after preparatory therapy and after training with the neuroprosthesis.

Walking performance with the neuroprosthesis improved with continued use. After the participant completed 12 weeks of training with the implanted FES system, his maximal walking distance increased from $14 \mathrm{~m}$ to $309 \mathrm{~m}$ and his maximal walking speed increased tenfold from $0.02 \mathrm{~m} / \mathrm{s}$ to $0.20 \mathrm{~m} / \mathrm{s}$. An additional effect of FES appeared to be a decrease in variability and an increase in consistency of contractions produced in partially paralyzed knee extensor muscles; the contractions were more consistent and sustained with stimulation after training, although not necessarily stronger. Walking efficiency increased with practice as evidenced by a fivefold decrease in PCI from 44 beats $/ \mathrm{m}$ to 8.6 beats $/ \mathrm{m}$. Sustained use of the system also produced gains in cardiovascular function, energy cost, and increased general cardiopulmonary health. Future systems will use implanted command-control sources to practically integrate stimulation with voluntary function via the EMG activity of the partially paralyzed musculature, thereby eliminating switches and body-worn sensors and adapting to volitional speed changes.

\section{ACKNOWLEDGMENTS}

We acknowledge the support of the VA Rehabilitation Research and Development Service, the contributions of 
our research volunteers and their families, and the surgical guidance of E. B. Marsolais, MD.

This material was based on work supported by the VA Rehabilitation Research and Development Service (merit review grant B2933R to Dr. Triolo).

The authors have declared that no competing interests exist.

\section{REFERENCES}

1. Sekhon LH, Fehlings MG. Epidemiology, demographics, and pathophysiology of acute spinal cord injury. Spine. 2001; 26(24 Suppl):S2-12. [PMID: 11805601]

2. Berkowitz M. The economic consequences of traumatic spinal cord injury. New York (NY): Demos; 1992.

3. Elder CP, Apple DF, Bickel CS, Meyer RA, Dudley GA. Intramuscular fat and glucose tolerance after spinal cord injury-A cross-sectional study. Spinal Cord. 2004;42(12): 711-16. [PMID: 15303112]

4. Phillips WT, Kiratli BJ, Sarkarati M, Weraarchakul G, Myers J, Franklin BA, Parkash I, Froelicher V. Effect of spinal cord injury on the heart and cardiovascular fitness. Curr Probl Cardiol. 1998;23(11):641-716. [PMID: 9830574]

5. Edwards BG, Marsolais EB. Metabolic responses to arm ergometry and functional neuromuscular stimulation. J Rehabil Res Dev. 1990;27(2):107-14. [PMID: 2366194]

6. Mahoney ET, Bickel CS, Elder C, Black C, Slade JM, Apple D Jr, Dudley GA. Changes in skeletal muscle size and glucose tolerance with electrically stimulated resistance training in subjects with chronic spinal cord injury. Arch Phys Med Rehabil. 2005;86(7):1502-4.

[PMID: 16003691]

7. Lew RD. The effects of FNS on disuse osteoporosis. Proceedings of the 10th Annual Conference of Rehabilitation Engineering Society of North America; 1987; San Jose, CA. Washington (DC): RESNA Press; 1987. p. 616-17.

8. Betz R, Boden B, Triolo R, Mesgarzadeh M, Gardner E, Fife R. Effects of functional electrical stimulation on the joints of adolescents with spinal cord injury. Paraplegia. 1996;34(3):127-36. [PMID: 8668353]

9. Triolo RJ, Bogie K. Lower extremity applications of functional neuromuscular stimulation after spinal cord injury. Top Spinal Cord Inj Rehabil. 1999;5(1):44-65.

10. Bajd T, Andrews BJ, Kralj A, Katakis J. Restoration of walking in patients with incomplete spinal cord injuries by use of surface electrical stimulation-Preliminary results. Prosthet Orthot Int. 1985;9(2):109-11. [PMID: 4047919]

11. Ferguson AC, Granat MH. Evaluation of functional electrical stimulation for an incomplete spinal cord injured patient. Physiotherapy. 1992;78(4):253-56.
12. Johnston TE, Finson RL, Smith BT, Bonaroti DM, Betz RR, Mulcahey MJ. Functional electrical stimulation for augmented walking in adolescents with incomplete spinal cord injury. J Spinal Cord Med. 2003;26(4):390-400.

[PMID: 14992342]

13. Chaplin E. Functional neuromuscular stimulation for mobility in people with spinal cord injuries. The Parastep I System. J Spinal Cord Med. 1996;19(2):99-105.

[PMID: 8732878]

14. Gallien P, Brissot R, Eyssette M, Tell L, Barat M, Wiart L, Petit H. Restoration of gait by functional electrical stimulation for spinal cord injured patients. Paraplegia. 1995; 33(11):660-64. [PMID: 8584301]

15. Winchester P, Carollo JJ, Habasevich R. Physiologic costs of reciprocal gait in FES assisted walking. Paraplegia. 1994;32(10):680-86. [PMID: 7831075$]$

16. Nash MS, Jacobs PL, Montalvo BM, Klose KJ, Guest RS, Needham-Shropshire BM. Evaluation of a training program with SCI paraplegia using the Parastep I ambulation system: Part 5. Lower extremity blood flow and hyperemic responses to occlusion are augmented by ambulation training. Arch Phys Med Rehabil. 1997;78(8):808-14.

[PMID: 9344298]

17. Thrasher TA, Flett HM, Popovic MR. Gait training regimen for incomplete spinal cord injury using functional electrical stimulation. Spinal Cord. 2006;44(6):357-61. [PMID: 16249784]

18. Ladouceur M, Barbeau H. Functional electrical stimulation-assisted walking for persons with incomplete spinal injuries: Longitudinal changes in maximal overground walking speed. Scand J Rehabil Med. 2000;32(1):28-36. [PMID: 10782939]

19. Wieler M, Stein RB, Ladouceur M, Whittaker M, Smith AW, Naaman S, Barbeau H, Bugaresti J, Aimone E. Multicenter evaluation of electrical stimulation systems for walking. Arch Phys Med Rehabil. 1999;80(5):495-500. [PMID: 10326910]

20. Granat MH, Ferguson AC, Andrews BJ, Delargy M. The role of functional electrical stimulation in the rehabilitation of patients with incomplete spinal cord injury-Observed benefits during gait studies. Paraplegia. 1993;31(4):207-15. [PMID: 8493035$]$

21. Popovic MR, Curt A, Keller T, Dietz V. Functional electrical stimulation for grasping and walking: Indications and limitations. Spinal Cord. 2001;39(8):403-12.

[PMID: 11512070]

22. Lyons GM, Sinkjaer T, Burridge JH, Wilcox DJ. A review of portable FES-based neural orthoses for the correction of drop foot. IEEE Trans Neural Syst Rehabil Eng. 2002; 10(4):260-79. [PMID: 12611364$]$ 
23. Petrofsky JS, Phillips CA. Closed-loop control of movement of skeletal muscle. Crit Rev Biomed Eng. 1985; 13(1):35-96. [PMID: 3902360]

24. Kralj A, Bajd T, Turk R, Krajnik J, Benko H. Gait restoration in paraplegic patients: A feasibility demonstration using multichannel surface electrode FES. J Rehabil Res Dev. 1983;20(1):3-20. [PMID: 6887064]

25. Kralj AR, Bajd T. Functional electrical stimulation: Standing and walking after spinal cord injury. Boca Raton (FL): CRC Press Inc; 1989. p. 123-38.

26. Kilgore KL, Peckham PH, Keith MW, Thrope GB, Wuolle KS, Bryden AM, Hart RL. An implanted upper-extremity neuroprosthesis: Follow-up of five patients. J Bone Joint Surg Am. 1997;79(4):533-41. [PMID: 9111397]

27. Kobetic R, Marsolais EB. Synthesis of paraplegic gait with multichannel functional neuromuscular stimulation. IEEE Trans Rehabil Eng. 1994;2(2):66-79.

28. Bohannon RW, Smith MB. Interrater reliability of a modified Ashworth scale of muscle spasticity. Phys Ther. 1987; 67(2):206-7. [PMID: 3809245]

29. American Spinal Injury Association. Standards for neurological and functional classification of spinal cord injury. Chicago (IL): American Spinal Injury Association; 1992.

30. Perry J, Garrett M, Gronley J, Mulroy SJ. Classification of walking handicap in the stroke population. Stroke. 1995; 26(6):982-89. [PMID: 7762050]

31. Field-Fote EC, Fluet GG, Schafer SD, Schneider EM, Smith R, Downey PA, Ruhl CD. The Spinal Cord Injury Functional Ambulation Inventory (SCI-FAI). J Rehabil Med. 2001;33(4):177-81. [PMID: 11506216]

32. Memberg WD, Peckham PH, Keith MW, Gazdik M. A surgically-implanted intramuscular electrode for an implantable neuromuscular stimulation system. Proceedings of the Annual International Conference of the IEEE Engineering in Medicine and Biology Society. Vol. 5. 1989 Nov 9-12; Seattle, WA. New York (NY): IEEE; 1989. p. 1520-21.

33. Smith B, Tang Z, Johnson MW, Pourmehdi S, Gazdik MM, Buckett JR, Peckham PH. An externally powered, multichannel implantable stimulator for control of paralyzed muscle. IEEE Trans Biomed Eng. 1987;45(4):463-75.

[PMID: 9556963]

34. Letechipia JE, Peckham PH, Gazdik M, Smith B. In-line lead connector for use with implanted neuroprosthesis. IEEE Trans Biomed Eng. 1999;38(7):707-9. [PMID: 1879864]

35. Agarwal S, Triolo RJ, Kobetic R, Miller M, Bieri C, Kukke S, Rohde L, Davis JA Jr. Long-term user perceptions of an implanted neuroprosthesis for exercise, standing, and transfers after spinal cord injury. J Rehabil Res Dev. 2003; 40(3):241-52. [PMID: 14582528]

36. Peckham PH, Keith MW, Kilgore KL, Grill JH, Wuolle KS, Thrope GB, Gorman P, Hobby J, Mulcahey MJ, Carroll S, Hentz VR, Wiegner A, Implantable Neuroprosthesis
Research Group. Efficacy of an implanted neuroprosthesis for restoring hand grasp in tetraplegia: A multicenter study. Arch Phys Med Rehabil. 2001;82(10):1380-88. [PMID: 11588741]

37. Buckett J, Triolo RJ, Ferencz D, Katorgi M, Bieri C. A wearable controller for clinical studies involving multiimplant FNS systems. J Spinal Cord Med. 1998;21(2):179.

38. Waters RL, Yakura JS, Adkins R, Barnes G. Determinants of gait performance following spinal cord injury. Arch Phys Med Rehabil. 1989;70(12):811-18. [PMID: 2818152]

39. Field-Fote EC. Combined use of body weight support, functional electric stimulation, and treadmill training to improve walking ability in individuals with chronic incomplete spinal cord injury. Arch Phys Med Rehabil. 2001; 82(6):818-24. [PMID: 11387589]

40. Davis RB, Ounpuu S, Tyburski D, Gage JR. A gait analysis data collection and reduction technique. Hum Mov Sci. 1991;10:575-87.

41. Kadaba MP, Ramakrishnan HK, Wootten ME. Measurement of lower extremity kinematics during level walking. J Orthop Res. 1990;8(3):383-92. [PMID: 2324857]

42. Guyatt GH, Sullivan MJ, Thompson PJ, Fallen EL, Pugsley SO, Taylor DW, Berman LB. The 6-minute walk: A new measure of exercise capacity in patients with chronic heart failure. Can Med Assoc J. 1985;132(8):919-23.

[PMID: 3978515$]$

43. MacGregor J. The evaluation of patient performance using long-term ambulatory monitoring technique in the domiciliary environment. Physiotherapy. 1981;67(2):30-33. [PMID: 7312961]

44. IJzerman MJ, Baardman G, Hermens HJ, Veltink PH, Boom HB, Zilvold G. The influence of the reciprocal cable linkage in the advanced reciprocating gait orthosis on paraplegic gait performance. Prosthet Orthot Int. 1997;21(1): 52-61. [PMID: 9141126]

45. Potter JM, Evans AL, Duncan G. Gait speed and activities of daily living function in geriatric patients. Arch Phys Med Rehabil. 1995;76(11):997-99. [PMID: 7487453]

46. Holden MK, Gill KM, Magliozzi MR, Nathan J, PiehlBaker L. Clinical gait assessment in the neurologically impaired. Reliability and meaningfulness. Phys Ther. 1984; 64(1):35-40. [PMID: 6691052]

47. Winter DA. Overall principle of lower limb support during stance phase of gait. J Biomech. 1980;13(11):923-27. [PMID: 7275999]

Submitted for publication February 8, 2006. Accepted in revised form January 26, 2007. 